\title{
A DIFÍCIL ARTE DE "DESLIZAR SOBRE O MUNDO" OU MONTAIGNE, UM POLÍTICO DISCRETO (“DE POUPAR A PRÓPRIA VONTADE" - III, 10)
}

\author{
Andre Scoralick* \\ andrescoralick@usp.br
}

RESUMO De 1581 a 1585, Montaigne foi prefeito de Bordeaux. Foi acusado por detratores de não se ter aplicado o bastante e de não ter feito nada de marcante durante seus dois mandatos. Ao responder às acusações no ensaio "De poupar a própria vontade" (III, 10), o autor encontra a ocasião para uma crítica das paixões em geral e, em particular, das que pertencem ao contexto político. Isto porque ele visava, com sua aparente falta de aplicação aos deveres de prefeito, evitar a paixão que tantas vezes se oculta por trás do engajamento - a ambição, desejo de honras, glória, renome. Sobretudo, esperava evitar um duplo perigo, ao mesmo tempo ético e político: comprometer a própria liberdade numa busca servil da glória e subordinar o bem coletivo a interesse pessoal. No presente estudo, procuraremos reconstituir a trama argumentativa do ensaio em questão, acompanhando de perto os argumentos que sustentam a critica montaigniana das paixões, bem como a terapia muito particular a que o ensaísta as submete, a qual lhe permite fazer do episódio da Mairie de Bordeaux um modelo de conciliação entre o cuidado de si e o cumprimento dos deveres políticos.

Palavras-chave Paixão; Ambição; Servidão; Perturbação; Liberdade; Tranquilidade.

* Doutorando em Filosofia na USP. Artigo recebido em 26/06/2012 e aprovado 08/08/2012. 
ABSTRACT From 1581 to 1585 Montaigne was the mayor of Bordeaux. He was accused by detractors of not having been sufficiently dedicated to his functions and of having done nothing remarkable during his two terms. In answering to such charges in the essay "Of Managing the Will" (III, 10), the author finds the occasion for criticising passions in general and, in particular, those concerning the political context. The reason for it is that he sought, with his apparent lack of commitment to the mayor's duties, to avoid the passions which usually hide behind such an engagement: ambition, desire for honours, glory, renown. Above all he hoped to avoid a double danger, both ethical and political: to compromise his freedom in a servile pursuit of glory and to subordinate the common good to his personal advantage. In the present study we will seek to rebuild the argumentative plot of the essay, following closely the reasoning which supports the Montaignean critique of passions and also the very particular therapy to which the essayist submits them, which allows him to turn the Mairie de Bordeaux episode into a conciliation model between the care of the self and the fulfillment of political duties.

Keywords Passion; Ambition, Servitude; Disturbance; Freedom; Calmness.

A duplicidade do título do presente estudo ${ }^{1}$ não é casual. Ela procura refletir os dois planos do ensaio de que nos propomos tratar - um texto simultaneamente ético e político, no qual Montaigne realiza uma crítica das paixões, propõe um modo de regulação das condutas individuais e, ao mesmo tempo, debruça-se sobre o campo da política, empreendendo uma crítica da ambição. Em seu primeiro plano, o propósito do capítulo "De poupar a própria vontade" é ético e seu teor é prescritivo: trata-se de uma crítica das paixões, da recusa da afeição excessiva às coisas, da adesão demasiadamente estreita do sujeito a tudo o que lhe é alheio e da servidão a que tal adesão conduz. Neste ensaio, Montaigne propõe uma verdadeira ménagerie ${ }^{2}$, mas a casa a

1 Utilizamos como fonte das citações dos Ensaios a edição Villey-Saulnier, que traduzimos livremente, cotejando com a tradução de Rosemary Costek Abílio da editora Martins Fontes. Como se poderá notar, acatamos frequentemente as soluções da tradutora. Nas referências aos Ensaios, o algarismo romano refere-se ao livro e os algarismos arábicos referem-se em sequência ao capítulo e à página da edição de Villey.

2 O título original do ensaio é De mésnager sa volonté. Mésnager é a ação relativa à mesnagerie, a arte da administração doméstica, disciplina que estabelece e executa as regras da gestão da casa (mesnage) 
ser administrada é o eu. Ele prescreve ao leitor a regulação de seus próprios afetos, de maneira que encontre a justa medida em sua aplicação às coisas e resguarde sua liberdade em relação às mesmas. O quadro (helenístico) é conhecido: trata-se de guardar certa distância em relação às coisas exteriores, a tudo que não está sob o nosso poder, mas sob o poder da Fortuna, podendo ser-nos surrupiado a qualquer momento e sem maiores razões, lançando no desespero e no tormento aqueles que não souberam guardar tal distância - que não souberam evitar as paixões. Montaigne pretende nos ensinar a difícil arte de "deslizar sobre o mundo" (glisser le monde), de evitar "mergulhar muito a fundo nas coisas" (s'y enfoncer) (III, 10, 1005); pretende nos ensinar, enfim, a assegurarmos a tranquillitas.

Este, no entanto, é apenas o horizonte mais geral do ensaio, pois a crítica das paixões em "De poupar a própria vontade" realiza-se, sobretudo, num contexto em particular - o da política. Neste texto, Montaigne alerta o leitor para o risco da perda da própria liberdade numa circunstância precisa: a da dedicação à vida pública e às ocupações e cargos políticos. O ensaísta opõe a intranquilidade dos homens que se entregam à vida pública (que se deixam sufocar e arrastar por suas ocupações e cargos) à tranquilidade com que ele próprio desempenhou a função de prefeito ${ }^{3}$ de Bordeaux, como ele o diz: "Consegui misturar-me com os cargos públicos sem afastar-me de mim sequer a distância de uma unha, e dar-me a outrem sem me tirar de mim mesmo" (III, 10, 1007).

Mas, a crítica das paixões tem principalmente um alcance político em "De poupar a própria vontade", pois os afetos comprometem a eficácia e a justiça da ação política, levam os indivíduos a subordinarem o bem comum aos seus interesses privados; cindem a sociedade em seitas e partidos, lançam os cidadãos e as nações nas mais graves disputas. Em "De poupar a própria vontade", Montaigne se debruça sobre a paixão política por excelência: a ambição, o desejo de honras, renome, glória. Acima de tudo, o ensaio faz a crítica desta paixão, pois os homens que se entregam apaixonadamente à vida pública quase sempre o fazem porque visam a projeção pessoal e, com isso, comprometem não apenas a própria liberdade, mas igualmente a liberdade da cidade.

e do governo da família e que, na França do século XVI, equivalia à oikonomia dos antigos. O termo é empregado por Montaigne no contexto de uma crítica das paixões. Ele prescreve ao leitor a boa gestão de seus próprios afetos (o termo vontade é utilizado em um sentido amplo), cuja aplicação sobre os objetos exteriores ele deve moderar, de modo a evitar a afeição excessiva e a intranquilidade e servidão que dela decorrem.

3 Maire, no original. A tradução é aproximada, uma vez que as funções do maire, no tempo de Montaigne, não correspondem exatamente às de um atual prefeito. 
Montaigne foi um político discreto. Foi acusado por detratores de não ter feito nada de marcante enquanto esteve à frente da prefeitura de Bordeaux - seus mandatos não teriam deixado vestígios. Em "De poupar a própria vontade", a crítica da ambição permite-lhe responder aos ataques: sua administração discreta foi o feito de um homem que não buscava se projetar, não procurava o destaque diante dos olhos do público, não colocava o interesse privado (o desejo de honras) à frente do bem comum. Também foi obra de um homem que conhece as ilusões da ambição, a intranquilidade e a servidão dos que são movidos por ela. De tal forma que seu mandato à frente da prefeitura de Bordeaux - espécie de conciliação paradigmática entre o cuidado de si e o cumprimento dos deveres políticos - é mais do que um simples dado biográfico, mera curiosidade sobre sua vida: é peça-chave para a compreensão da ética e da política que nos oferece com seus Ensaios.

\section{Crítica da Servidão às Paixões e Prescrição de uma Terapia}

Acompanhemos, então, a trama argumentativa do ensaio. Montaigne começa-o com um curto proêmio, no qual formula a prescrição em torno da qual se constrói todo o capítulo. Ele afirma que devemos evitar os afetos excessivos. Afirma-o, sobretudo, visando uma circunstância específica: a ocupação dos cargos e funções políticas. Tal prescrição visa nos auxiliar a evitar a servidão e a intranquilidade.

O ensaísta parte do quadro legado pela tradição helenística ${ }^{4}$. Aquele que se apaixona por algo (que experimenta uma afeição ou aversão excessivas) prende-se ao objeto amado ou temido e perde a própria liberdade. Passa a viver em função de tal objeto, ocupando-se dele mesmo quando não está presente, pois seus pensamentos permanecem retidos nele. De tal forma que o apaixonado está sempre fora de si, preso ao objeto da paixão. É uma consciência que não vive o aqui e o agora, que está sempre alhures: no passado, no futuro, noutro lugar. Enfim, é alguém que perdeu o domínio sobre si mesmo (a autarquia), pois seus atos e pensamentos são comandados por aquilo que ama ou teme.

4 A referência mais imediata do ensaio que ora analisamos é o De tranquillitate animi, texto em que Sêneca formula prescrições para aquele que deseja assegurar a tranquilidade da alma (tranquillitas). Na verdade, todo o ensaio montaigniano parece ser uma espécie de amplificação, realizada no interior do quadro da experiência do autor, da primeira prescrição senequiana: "parcius se inserat officiis" (cf. De tranquillitate animi, IV, 2). Como veremos, Montaigne parece partir da formulação senequiana do problema, mas recusar a resposta do filósofo romano. 
Contra o risco de tal servidão (e ainda de acordo com os ditames da ética antiga), Montaigne propõe uma terapia das paixões. Os termos em que esta se deve dar serão apresentados mais adiante, mas sua prescrição é feita logo no proêmio, por meio de uma contraposição entre o modo de agir do ensaísta, que a aplica, e o dos homens em geral (le commun des hommes) que se deixam dominar. Montaigne começa dizendo que as coisas o afetam, mas pouco; que ele deseja e teme, mas não a ponto de deixar-se prender. Diz que procura reforçar "pelo estudo e pelo discurso" (III, 10, 1003) esta propensão que reconhece em si mesmo, esforçando-se para restringir a poucas coisas os laços afetivos estreitos ("esposo [...] poucas coisas" - III, 10, idem). Conta-nos, enfim, que dirige seus afetos para si mesmo e opõe-se com todas as forças às paixões que o prendem alhures. E conclui: "minha opinião é que devemos emprestar-nos a outrem e darmo-nos apenas a nós mesmos" (III, 10, idem).

Este modo de agir vale para a relação com tudo que lhe é alheio ${ }^{6}$. Mas Montaigne imediatamente se volta para um campo determinado: o da relação com outrem. Diz que nas ocasiões em que o solicitaram a cuidar de negócios alheios (affaires estrangieres) comprometeu-se a encarregar-se deles ( $m$ 'en charger), mas não a entregar-se apaixonadamente à tarefa ( $m$ 'en passionner nullement - III, 10, 1004). Em oposição, então, descreve o comportamento da maioria dos homens, que são servis. Eles comprometem-se a fundo em toda e qualquer tarefa de que se encarregam, sem discriminação de ocasião ou importância ("nas pequenas coisas como nas grandes, no que não lhes toca como no que lhes toca" - III, 10, idem); são propensos a uma vida servil e intranquila ("tão servis para seus amigos quanto importunos para si mesmos"III, 10, idem). Contrário a esta conduta, o ensaísta recomenda a discriminação das ocasiões e assuntos que realmente exigem um comprometimento maior um discernimento que deve comandar o trabalho sobre os afetos.

\section{Circunscrição ao Campo Político. A Justa Medida do Amor de Si.}

Imediatamente, então, Montaigne passa para o campo da política, relatando as circunstâncias em que assumiu a prefeitura de Bordeaux. Contanos que disse aos que lhe impuseram o cargo que não comprometeria a própria liberdade com uma aplicação excessiva à nova ocupação, como fizera

5 O sentido desta conduta, inteiramente conforme, aliás, aos preceitos da ética helenística, será analisado mais adiante.

6 Um dos pontos mais sensíveis do ensaio - aliás, de todos os Ensaios - é justamente o dos limites entre o eu e o outro. Analisaremos este problema, tal como Montaigne o desenvolve neste ensaio, mais adiante. 
seu pai quando, anos antes, conduzira a cidade. A dedicação desmedida de Pierre Eyquem aos assuntos públicos, no entanto, não configura um vício aos olhos do ensaísta, posto que visava o interesse coletivo, não a projeção pessoal ("jamais houve alma mais caridosa e popular" - III, 10, 1006), não sendo pautada por uma intenção pervertida. Apesar disso, não deixa de the parecer um comportamento a ser evitado - até porque se apoia numa opinião que ele considera falsa: aquela segundo a qual a coletividade vale mais e tem precedência sobre o indivíduo, que deve se sacrificar em seu nome. Recorrendo, então, à justa medida do amor de si, Montaigne refuta o preceito que teria pautado o modo de agir de seu pai, mostrando que o indivíduo, ao contrário do que Pierre Eyquem pensava, deve alguma atenção a si mesmo: "Quem conhece seus deveres descobre em seu papel que deve aplicar a seu favor o uso dos outros homens e do mundo, e, para fazê-lo, contribuir para a sociedade pública com os deveres e ofícios que lhe tocam" (III, 10, idem). Numa única e mesma frase, o ensaísta formula as duas exigências que devem ser satisfeitas: a do indivíduo (aplicar os outros a seu favor) e a da coletividade (aplicar-se em favor dos outros).

Tudo se passa, no entanto, como se tal equilíbrio fosse o meio do caminho entre dois polos contraditórios: devo me dedicar um pouco menos à cidade para me preservar; devo me dedicar um pouco menos a mim mesmo, pois tenho deveres em relação à coletividade. Seria como se as exigências pessoais e as da cidade se opusessem e o indivíduo tivesse de temperar uma com a outra. Ora, não é este o sentido da justa medida proposta por Montaigne, pois imediatamente ele afirma que não prescreve uma dedicação menor às tarefas políticas ("não quero que recusemos aos cargos que tomamos a atenção, os passos, as palavras, nem o suor e o sangue se for preciso" - III, 10, 1007), apenas recusa a presença da paixão em seu exercício ("não sem ação, mas sem vexação" - idem). Este é o elemento a ser combatido. Por meio deste combate, o indivíduo atenderá às suas próprias prerrogativas (assegurará sua liberdade e tranquilidade) e, ao mesmo tempo e igualmente, atenderá às prerrogativas da cidade, que será beneficiada por uma ação política mais eficaz e mais justa, porque não apaixonada. Inversamente (poderíamos imaginar), o indivíduo que se entrega apaixonadamente às ocupações políticas sacrifica a si mesmo bem como a cidade - compromete sua própria liberdade e a condução dos assuntos públicos. De tal forma que não há tensão, mas convergência entre os interesses da cidade e os do indivíduo: o bem de um implica o bem do outro, como o mal de um, o mal do outro. Neste ponto, Montaigne permanece estreitamente alinhado com os antigos. 


\section{Afastar a Paixão em nome da Ação. Montaigne Agente.}

Busquemos compreender melhor a segunda parte do problema - isto é, de que maneira a entrega apaixonada do indivíduo às funções públicas compromete os interesses da cidade. Montaigne se ocupa desta questão em um novo movimento argumentativo do ensaio, no qual distingue a ação da paixão e aponta o erro dos que veem mais ação no envolvimento apaixonado com determinada atividade e menos ação numa relação fria e desinteressada. Ocorre, diz o ensaísta, justamente o contrário: a paixão reduz o espaço da ação, consome as forças do agente e obscurece seu raciocínio, mergulha-o na ansiedade e na desordem de espírito, apressa o andamento das coisas e impede a calma consideração das circunstâncias ("esta aspereza e violência de desejo mais impede do que serve à condução do que empreendemos" - III, 10, 1007). Ação e paixão, diz Montaigne, são mutuamente excludentes ("uma vai bem sem a outra" - idem), como comprova a experiência. Afinal, vê-se frequentemente um desempenho melhor naqueles que mantêm uma relação desinteressada com a atividade, enquanto se constata a inércia de homens profundamente preocupados com os mesmos eventos ("têm a alma mais absorvida [pela guerra] do que o soldado que nela emprega seu sangue e sua vida" - idem). A paixão, enfim, não leva à ação e ainda a atrapalha, pois a preocupação excessiva com os resultados da ação (a expectativa de que o fim seja alcançado) prejudica o bom andamento dos meios: "Aquele que se porta mais moderadamente em relação à vitória e à derrota está sempre em si mesmo; quanto menos aguilhoa-se e apaixona-se pelo jogo, com tanto mais vantagem e segurança o conduz" (III, 10, 1009). Daí o erro dos que se entregam apaixonadamente à vida pública. Eles comprometem a eficácia e a justiça de suas ações, que só podem advir de uma fria ponderação. Daí a recomendação montaigniana para que se coloque em prática uma terapia dos desejos e das aspirações que corrija nossa relação com os fins.

\section{Economia dos Desejos e Aspirações. Os Costumes como Medida.}

Um novo movimento do ensaio, então, dedica-se a formular esta terapia. Toda uma tradição já denunciara os mecanismos perversos da paixão, que põem o sujeito num movimento perpétuo, numa busca sem fim, em que cada objeto alcançado imediatamente perde o brilho diante de outro que chama atenção à distância - movimento acompanhado de insatisfação e ansiedade permanentes. Montaigne segue de perto esta tradição, assimila sua crítica das paixões e até mesmo parece adotar a terapia que ela propõe - mas altera 
significativamente seus termos. Vejamos a passagem em que começa a apresentar sua própria versão da terapêutica dos afetos:

De resto, impedimos a captura e a retenção pela alma ao lhe darmos tantas coisas para agarrar. Algumas, devemos apenas apresentar-lhe; outras, atar; outras, incorporar. Ela pode ver e sentir todas as coisas, mas deve alimentar-se apenas de si, e deve ser instruída quanto ao que lhe concerne propriamente, e que propriamente faz parte de seus haveres e de sua substância. As leis da natureza nos ensinam o que exatamente nos é necessário. (...) os sábios (...) distinguem sutilmente os desejos que provêm dela daqueles que provêm do desregramento de nossa imaginação (III, 10, 1009; grifo nosso).

Montaigne, como se vê, prescreve diferentes tipos de relação e níveis de afetividade ("ver e sentir", "atar a si", "incorporar a si", "alimentar-se") conforme os diferentes objetos, recomendando que evitemos afeiçoar-nos em excesso ("incorporar a si", "alimentar-se") ou que no-lo permitamos somente em relação a poucas coisas: àquelas que nos concernem, que fazem parte dos nossos haveres e substância. Segundo certa tradição ("os sábios”), trata-se dos objetos das nossas necessidades naturais (comer, beber etc.), aqueles pelos quais garantimos a conservação da nossa própria vida. Eles são "nossos haveres e substância" porque por meio deles (isto é, à medida que os buscamos) agimos com vistas à nossa preservação, à realização da nossa própria natureza; de tal forma que, quando os buscamos, visamo-nos, buscamo-nos. Todo excesso de afetividade por outros objetos que não os de nossas necessidades naturais (por exemplo, a honra ou a riqueza) é fonte de servidão e intranquilidade, pois é afeição por um outro sobre o qual não temos poder, e que pode ser-nos subtraído a qualquer momento pela Fortuna. Inversamente, quando buscamos apenas a satisfação das nossas necessidades naturais, desligamo-nos do outro e recuperamos a autarquia e a tranquilidade.

Ocorre que Montaigne, quando se volta para si mesmo e se examina, não encontra a natureza operando, mas somente os costumes que o determinam e constituem ("o que falta para o meu costume considero que me falta" - III, 10, 1010, grifos nossos). Assim, quando se permite apaixonar-se somente pelos objetos que concernem e pertencem ao eu (por aquilo, enfim, que não é outro), ele não restringe as paixões aos objetos das necessidades naturais, mas aos dos costumes do seu país, da sua cidade, da sua classe, da sua família ("taxemo-nos, tratemo-nos de acordo com esta medida, estendamos até lá nossos pertences e nossas contas" - III, 10, 1009). A medida dos afetos, pois, não é a da natureza, mas a do costume. De resto, Montaigne acrescenta que se trata de uma medida mais ampla e generosa (mais de acordo com o homem comum, que não é sábio) do que a prescrita pela tradição supracitada. Nem 
por isso, no entanto, deve ser obedecida com menos rigor: "é a maior extensão que podemos outorgar aos nossos direitos. Quanto mais amplificamos nossas necessidades e nossa posse, tanto mais nos comprometemos com os golpes da fortuna e das adversidades" (III, 10, 1011).

\section{A Política como Teatro. Recusa do Partidarismo sem Crítica.}

Interessa principalmente realizar esta terapia dos afetos no contexto político. Na sequência imediata do texto, então, Montaigne insiste que devemos nos aplicar às nossas funções, mas sem deixar de nos distinguir das mesmas - de separar a pessoa do cargo ocupado, o eu da função desempenhada: "É preciso representar devidamente nosso papel, mas como papel de um personagem emprestado" (III, 10, idem). Sem avançar sobre o problema do estatuto do eu e dos contornos que o determinam, o ensaísta prescreve certo distanciamento do sujeito em relação às funções que desempenha, as quais devem ser exercidas segundo o modelo da representação teatral. Ele recomenda o recuo crítico que permite ao ator aplicar-se integralmente à execução do papel e, ao mesmo tempo, assegurar a integridade do eu: "da máscara e da aparência não devemos fazer uma essência real, nem do alheio o próprio" (idem). Sem investigar o problema da alienação, que ocupará as reflexões de pensadores posteriores, Montaigne parece chegar às suas portas, conduzido pelo problema da servidão. Aqui, o risco a ser combatido é o da perda da própria liberdade, do domínio sobre si mesmo, em função da afeição excessiva aos cargos e funções. O autor se apresenta, enfim, como modelo na prevenção deste risco: "o prefeito e Montaigne sempre foram dois, por uma separação bem clara” (III, 10, 1012).

Não se trata, no entanto, de uma defesa do uso da máscara - do ocultamento e da dissimulação, da manipulação do outro no espaço público em favor de seus próprios interesses privados. Trata-se, justamente ao contrário, de demarcar com clareza as fronteiras do público e do privado, de prescrever para o homem privado um recuo crítico em relação aos cargos que ocupa, que lhe permita atender aos seus interesses privados (assegurar sua liberdade e tranquilidade), enquanto, ao mesmo tempo, abre-lhe espaço para buscar o interesse público - o bem comum. O ambicioso, que se afeiçoa vaidosamente aos cargos que ocupa, busca no exercício da vida pública a realização de fins privados - procura a satisfação pessoal nas honras que conquista como homem público. Ao fazêlo, contudo, compromete tanto a sua satisfação pessoal (pois permanece intranquilo, sempre em busca de mais honras e com medo de perder as que já conquistou) quanto o interesse público, que ele mantém subordinado aos seus 
interesses privados. Ao combater a afeição pelos cargos (ao distinguir-se dos papéis que ocupa), ele pode finalmente encontrar a tranquilidade que a busca da honra não lhe trazia, ao mesmo tempo em que passa a poder buscar, no exercício dos cargos, o fim próprio da vida pública - o bem comum.

O mesmo movimento é realizado por Montaigne quando examina a relação do indivíduo com o partido a que pertence - no caso, o partido religioso. Em nenhum momento o ensaísta recusa a adesão convicta a um grupo, nem mesmo a certeza de que se trata da melhor das posições ("eu me agarro firmemente ao mais são dos partidos" - III, 10, 1013), mas recusa a adesão sem crítica, a incapacidade para discriminar os erros dos aliados e reconhecer os acertos dos adversários - a conduta, enfim, da maioria dos homens, tão contrária ao seu modo de agir: "quando minha vontade entrega-me a um partido, não é com uma obrigação tão violenta que infecte meu entendimento. (...) Eles adoram tudo o que está do seu lado: eu nem sequer desculpo a maior parte das coisas que vejo do meu" (III, 10, 1012). A maioria dos homens adere integralmente a um dos lados, daí a incompreensão que sofreram as opiniões do ensaísta: "Ele é da Liga, pois admira a graça do Senhor de Guise. A atividade do Rei de Navarra maravilha-o: ele é huguenote." (III, 10, 1013)

Ora, os indivíduos são incapazes de criticar o partido a que pertencem porque a crítica também os afetaria, uma vez que, apaixonados, não se distinguem do grupo. Eis porque se encolerizam quando outros o atacam: defendem-se a si próprios, quando defendem o partido. Mas qual é exatamente o objeto da paixão que os arrasta? A causa do partido, que creem representar melhor o bem da coletividade? Poderíamos até admitir que a crítica de Montaigne atinja lateralmente este apaixonado bem intencionado (como de alguma forma parecia atingir, no começo do ensaio, o engajamento apaixonado de seu pai), mas ela visa, antes de tudo, outra figura: o indivíduo que não critica o grupo porque tem interesses pessoais vinculados a ele, tendo a ganhar com sua vitória e a perder com sua derrota ("eles não se interessam pela causa comum, enquanto ela fere o interesse de todos e do estado, mas somente enquanto os machuca privadamente. Eis porque são aguilhoados por ela em função de paixão particular e para além da justiça e da razão pública." - III, 10, 1012). Interesses privados são o objeto de sua paixão, à qual Montaigne se opõe francamente: "meu interesse não me fez desconhecer nem as qualidades louváveis em nossos adversários, nem aquelas que são repreensíveis naqueles que segui" (III, 10, 1013).

Uma terapia das paixões, enfim, é a condição do recuo crítico em relação ao partido. Quem ganha com isso é o interesse geral. Ganha também o indivíduo, que não mais se perturba diante das derrotas do grupo. Ganha, 
enfim, o próprio partido: "prejudicamos os partidos justos quando queremos socorrê-los [a todo custo]. Sempre me opus a isto. Tal expediente só ocorre às cabeças doentes; para as saudáveis, há vias mais seguras e não somente mais honestas para manter a moral e aliviar os acidentes contrários" (III, 10, 1014).

\section{A Terapia das Paixões. O Momento Oportuno. Diversão versus Con- tenção.}

É necessário, pois, avançar na definição dos preceitos de uma terapia das paixões. Montaigne começara a fazê-lo algumas páginas atrás. Agora, aprofundar-se-á na tarefa. Ele começa lembrando que certos sábios da antiguidade não precisavam se preocupar com os afetos excessivos: eram fortes o bastante para se apaixonar e suportar tranquilamente a perda do objeto amado ("não temeram apegar-se e comprometer-se até o âmago com várias coisas" - III, 10, 1015). Sua força lhes permitia enfrentar as turbulências das paixões sem prejuízo para a própria tranquilidade ("estas pessoas estão seguras de sua força, sob a qual se protegem de todo tipo de acontecimento adverso, fazendo os males lutar em função do vigor da resistência" - idem). O ensaísta acrescenta que tais sábios, no entanto, não servem de modelo para a maioria dos homens (dentre os quais o próprio Montaigne se coloca), que são homens ordinários, não possuindo a força de um Catão ("não nos lancemos atrás destes exemplos; não os alcançaríamos" - idem). Em seu lugar, propõe o exemplo de outras figuras (Sócrates, Zenão e Ciro) que preferiam evitar o avanço dos afetos em vez de suportar os seus excessos. Montaigne traça, assim, uma oposição entre o enfrentamento que supõe a força (a enkrateia ou patientia) e uma estratégia que consiste em evitar o avanço dos afetos, lidando com eles enquanto ainda são incipientes. Os impulsos afetivos, neste contexto, são compreendidos segundo uma metáfora biológica - nascem e crescem, ganhando corpo. O homem comum, incapaz de suportar a tormenta, deve atuar sobre seus afetos enquanto ainda são frágeis, aproveitar o momento oportuno e agir assim que se despertam ou, de preferência, antes, quando prevê seu despertar ("sinto a tempo os ventinhos que me vêm roçar e sussurrar por dentro, precursores da tempestade" - III, 10, 1017).

Que gênero de ação Montaigne prescreve? Resistir às primeiras manifestações afetivas, fazendo frente aos objetos que inspiram medo ou desejo? Não. Talvez por desconfiar demais de suas forças ou da possibilidade de agir sobre os próprios afetos, o autor nunca propõe um embate ou ação direta sobre eles, nem mesmo enquanto incipientes. Em vez disso, a estratégia é a do desvio, da fuga; a terapia consiste em evitar o enfrentamento: "Sócrates 
não diz: - Não vos rendais aos atrativos da beleza, fazei frente a ela, esforçaivos contra ela! Ele diz: - Fugi dela!" (III, 10, 1015). Trata-se de evitar as circunstâncias e situações em que, por experiência, sabemos que nossos afetos tendem a se tornar excessivos; trata-se de evitar, enfim, a presença dos objetos ou imagens (pensamentos, lembranças) que os alimentam e intensificam: “outrora, eu gostava dos jogos de azar (...) desfiz-me deles há muito tempo, apenas porque, por mais que fizesse uma cara boa ao perder, não deixava de me sentir aguilhoado por dentro" (III, 10, 1015). E quando o encontro não puder ser evitado, que se busque o pronto afastamento da consciência, seu desvio (divertissement) para outros objetos ou representações: "Zenão, vendo aproximar-se Cremônides, jovem que ele amava, para sentar-se perto dele, levantou-se subitamente" (idem). De maneira semelhante, Montaigne constrói o discurso consolatório da famosa passagem do ensaio "Da experiência", procurando substituir a imagem assustadora de sua doença por uma representação mais favorável: "trato minha imaginação o mais suavemente que posso (...) Meu espírito é próprio para este serviço: (...) diz que é para o meu bem que eu tenho cálculos" (III,13, 1090). Incapaz de poder atuar sobre os próprios afetos, o homem comum deve agir sobre as representações que os mobilizam? ${ }^{7}$.

Deixaremos de lado a análise do movimento seguinte, em que Montaigne acusa a vanidade das disputas humanas e a vileza dos acordos que lhes põem fim, ambos fundados nas paixões, e nos dedicaremos diretamente ao movimento ulterior - a conclusão, mais imediatamente ligada ao ponto que nos interessa.

\section{Prestação de Contas e Crítica da Ambição: o Tato Político de Mon- taigne}

Passemos, portanto, à parte final do ensaio - fim que bem poderia servir de começo para o comentário. Pois, Montaigne conclui "De poupar a própria

7 A terapia montaigniana, enfim, diverge da que é proposta pelos céticos pirrônicos, bem como das terapias estoica e epicurista, pois não se trata de procurar uma representação antitética para opor a uma primeira phantasía e, com isso, obter a isostheneia e a ataraxia - como no caso dos pirrônicos. Nem de substituir uma interpretação falsa sobre uma representação (p. ex., "a morte é temível") por uma supostamente verdadeira ("a morte não é temível"), como no caso dos estóicos e epicuristas. Montaigne propõe o desvio da consciência de uma representação que provoca uma paixão (dor, tristeza, medo, cólera etc.), para uma outra que restitua a tranquilidade da alma, pouco importando seu conteúdo e, sobretudo, sua verdade ou falsidade. Vale, até mesmo, uma construção discursiva de cujo conteúdo a própria consciência desconfia. Ela sabe da precariedade da terapia ("se [meu espírito] persuadisse como prega, socorrer-me-ia com sucesso" - III, 13, p. 1090), mas a toma como o único recurso possível ("amanhã, providenciaremos outras escapatórias" - Idem, p. 1095). 
vontade" com uma prestação de contas de seu mandato à frente da prefeitura de Bordeaux. Ora, todo o capítulo pode ser compreendido como uma grande justificação do seu modo de agir quando ocupou este posto - empresa que lhe teria dado o ensejo para uma crítica das paixões, em geral, e da ambição, em particular. Na conclusão, então, Montaigne elenca as duas críticas que foram feitas aos seus mandatos. A primeira: não teria se aplicado o bastante em suas funções de prefeito, mas "como homem que se move por demais frouxamente e com uma vontade débil" (III, 10, 1020). Ao que ele responde: os que me dirigem esta crítica "não estão de modo nenhum distantes da verdade", pois "eu tento manter minha alma e meus pensamentos em repouso" (idem). Mais uma vez, o ensaísta mostra ter agido de acordo com a exigência ético-política da serenidade (a tranquillitas), de tal forma que a dosagem de sua aplicação não deve ser confundida com incapacidade ("pois falta de preocupação e falta de senso são duas coisas diferentes") ou falta de empenho ("mobilizei-me [pelo povo] como o faço por mim").

O ponto culminante do ensaio, no entanto, vem com a resposta dada por Montaigne à segunda crítica que lhe dirigem. Ele afirma que alguns o criticam por não ter feito nada de marcante durante seu mandato - nada que tivesse permanecido na memória de seus concidadãos: "dizem também que esse meu mandato passou sem deixar marca nem vestígio" (III, 10, 1021). Contra esta crítica, o ensaísta afirma que não deixou de lado nenhuma iniciativa que o dever tenha exigido ("aucun mouvement que le devoir requist en bon escient de moy"); que não levou adiante apenas as prescritas pela ambição ("ceux que l'ambition mesle au devoir et couvre de son titre" - idem). Diz ter desempenhado todas as tarefas que sua função de prefeito lhe impunha, mas não ter buscado se destacar aos olhos do povo. Se pôde cumprir seu dever "à noite, na Câmara do Conselho", assim o fez - não deixou para desempenhar suas tarefas "ao meio-dia, na praça pública". Montaigne sabe que os homens só se contentam com a visão das ações, que precisam vê-las em curso; do contrário, pensam que nada foi feito ("se não ouvem barulho, parece-lhes que estamos dormindo" - idem). Mas fez prevalecer um outro critério sobre o desejo de projeção pessoal: o dever. Assim, agiu de maneira diferente da maioria dos homens, que "[buscam] sua reputação e proveito particular, não o bem", como aqueles cirurgiões da Antiguidade, "que faziam as operações de sua arte sobre estrados à vista dos passantes, para adquirir (...) freguesia." (III, 10, 1022)

Tais considerações lhe dão o ensejo para uma crítica direta da ambição, empreendida por meio de dois argumentos. No primeiro, sustenta que ela não convém à maioria dos homens (entre os quais o próprio ensaísta se coloca), 
que são comuns, incapazes de ações dignas de glória e que, esperando granjear louvores por meio de ações corriqueiras, mostram tanto mais sua própria mediocridade ("eles querem atribuir-lhe o preço que ela[s] lhes custa[m]" - III, 10, 1023). No segundo, sustenta que a ambição é contraproducente, que a busca da honra só conduz à desonra, posto que implica numa postura servil ("Desdenhemos essa sede de fama e de honras, baixa e suplicante, que nos faz mendigá-las a toda espécie de pessoas [...], por meios abjetos e pelo preço vil que for. É desonra receber honras assim.”- idem). Louvável é a ação livre, cujo fim encontra-se nela mesma, no seu valor intrínseco. Aquela que se executa como meio para a projeção pessoal é feia e repreensível. Ora, os motivos que levam o agente às ações de destaque são sempre dignos de suspeita: "Na medida em que uma boa ação é mais ruidosa, vou descontando de seu valor a suspeita que começo a ter de que seja praticada mais por ser ruidosa do que por ser boa" (III, 10, 1023). A passagem se encerra, então, com o elogio da ação discreta: "Muito mais mérito têm as ações que escorregam da mão do autor despreocupadamente e sem alarde, e que depois algum homem de bem nota e resgata da sombra, impelindo-as para a luz por causa de si mesmas" - idem).

Terminada a crítica da ambição, Montaigne retorna à refutação de seus críticos, insistindo que agiu de acordo com as circunstâncias e visando unicamente o cumprimento de seu dever. Afinal, eram tempos de crise, uma época em que o tecido social do país, já tão esgarçado pelas guerras de religião, ameaçava romper-se em definitivo; um período, pois, em que intervenções incisivas (inovações) não eram recomendáveis, posto que agravariam ainda mais o quadro de crise (iniciado, aliás, por uma primeira inovação: a Reforma). Neste contexto, convinha ao político manter certa distância dos eventos, conduzir-se com delicadeza nas situações, observar e aguardar que os tumultos arrefecessem, intervindo somente quando necessário. Seguindo o modelo de uma medicina empírica, Montaigne se propôs a observar as evoluções da "doença" que acometia a cidade e a deixá-la, tanto quanto possível, seguir seu curso natural em direção ao arrefecimento - sabendo que, as mais das vezes, o remédio prejudica mais o corpo do que a doença. Esta ação cautelosa, enfim, visava conservar e prolongar (fazer durar) a ordem frágil que ainda subsistia no corpo social, esperando que o tempo e o arrefecimento dos ânimos lhe permitissem recuperar o vigor original. Ocorre que tal ação (a ação de conservação) é silenciosa e imperceptivel - apenas a inovação salta aos olhos. Seu senso de conveniência e sua profunda compreensão de seu tempo, portanto, forneceram a Montaigne os motivos para se manter à sombra. 


\section{Uma Ambição Morna e Discreta}

Terminada a leitura do ensaio, acreditamos ter dado alguma clareza à atuação política de Montaigne ou, mais precisamente, à sua posição a respeito das paixões (sobretudo, da ambição) no contexto político. Como vimos desde o proêmio do capítulo, o ensaísta se esforça para afastar esta paixão do horizonte da política, seja pelo risco que ela representa para a liberdade e a tranquilidade do indivíduo, seja porque os interesses públicos devem permanecer à frente dos interesses privados. De resto, a ambição não convém ao homem medíocre, figura que representa a maioria dos homens e na qual Montaigne se reconhece. De tal forma que, ainda que admitíssemos a existência de uma ambição montaigniana, ela não poderia ser senão objeto da terapia das paixões proposta pelo ensaísta. Lembremo-nos de suas palavras ainda no proêmio do ensaio: "Mas, às paixões que me distraem de mim e me prendem alhures, a essas certamente me oponho com todas as minhas forças" (III, 10, 1003).

Poderíamos, no entanto, desconfiar das razões alegadas pelo autor e suspeitar da aparente assepsia de sua atuação política, tal como a descreve no "De poupar a própria vontade". Poderíamos nos perguntar se Montaigne não é pouco sincero quando leva tão longe a crítica das paixões e se não oculta, por trás do que diz, alguma ambição. Afinal, todo o ensaio é uma defesa de sua atuação política, na qual ele parece exibir-se discretamente como um político zeloso, atento ao dever e às circunstâncias históricas. $\mathrm{O}$ texto, sem dúvida, parece ter esta intenção. Deveríamos inferir daí, então, uma ambição montaigniana? Como ela seria possível depois de um ataque tão longo e profundo às paixões? Como conciliar a trama argumentativa do ensaio com o efeito que, ao final, ele parece produzir no leitor (uma admiração imediata por um político tão zeloso e atento ao bem comum)?

Para responder a esta questão, devemos lembrar que a terapia montaigniana das paixões não tem como alvo a afetividade enquanto tal. Como vimos, o ensaísta prescreve uma economia dos afetos que visa evitar os excessos, dando lugar aos impulsos moderados. Retomando uma das frases que citamos anteriormente, vemos Montaigne a dizer que a alma "deve alimentar-se apenas de si", mas "pode ver e sentir todas as coisas" (III, 10, 1009, grifos nossos). Ainda que não seja definido com clareza ao longo do ensaio, o termo paixão indica o impulso que compromete a tranquilidade do agente, impede-o de agir e põe em xeque sua liberdade. É somente este impulso (um impulso excessivo) que deve ser evitado por meio da terapia da diversão, a qual abre caminho para uma ação tanto mais plena, equilibrada, justa e eficaz. Neste sentido, poderíamos admitir que Montaigne experimenta uma ambição 
morna e discreta, que ele busca a honra sem ansiedade, sem paixão - sem prender-se a este outro e escravizar-se a ele. E se seus argumentos pareceram frequentemente radicais ao longo da trama do ensaio, a ponto de nos fazer crer que atacavam a ambição e a afetividade tout court, isto se deve ao fato de que tinham como alvo um excesso - a cultura da ação notável, tão característica da época. Contra um excesso, apenas outro é eficaz - apenas o outro extremo é capaz de reconduzir à justa medida: como na "arte dos arqueiros, que para chegar ao ponto vão buscando a mira num grande espaço acima do alvo" (III, $10,1006)$.

\section{Montaigne Agente}

Se isto é verdade, se Montaigne assegura, por meio de uma busca morna da honra, sua tranquilidade e sua capacidade de ação, somos obrigados, por fim, a indagar os comentadores que defendem a tese da passividade do autor dos Ensaios ou que pretendem restringir o alcance de suas ações. Pensamos mesmo num grande clássico do comentário montaigniano, como o livro Montaigne, de Hugo Friedrich, que fez história com sua preciosa contribuição para o estudo da obra montaigniana e marcou diversos intérpretes posteriores ${ }^{8}$.

Friedrich insere sua leitura ${ }^{9}$ do ensaio "De poupar a própria vontade" no segundo momento do movimento dialético de humilhação e afirmação do homem, que ele acredita presidir a estrutura dos Ensaios. Ele considera que Montaigne fornece com sua atuação política mais um exemplo da afirmação da condição humana - frágil, contingente, complexa, mistura de bem e mal, razão e paixão. Segundo o comentador, o ensaísta restringiria ao máximo sua aplicação aos cargos públicos (obrigação que se lhe imporia) em nome de uma "livre disposição de si mesmo" (do máximo de espaço que pode conceder às próprias pulsões); optaria por um grau mínimo de intervenção sobre a ordem política em nome de um "deixar correr" que, no final das contas, convergiria favoravelmente com o andamento do mundo, o qual seria avesso às intervenções. Nesta concessão mínima à obrigação dos cargos entende Friedrich - Montaigne se ajustaria à sua condição humana mista: à

8 Vemos certa proximidade, por exemplo, entre as consequências que Frédéric Brahami tira da crítica cética montaigniana no seu livro Le Scepticisme de Montaigne e as que Friedrich extrai de sua leitura da Apologia a Raimond Sebond. Embora com diferentes matizes, os dois comentadores caminham na direção de um irracionalismo de tipo vitalista que, no caso de Friedrich, assenta-se - como sugerem suas constantes alusões a Goethe, Dilthey, Burckhardt e mesmo Nietzsche - em pressupostos de certa tradição do pensamento alemão.

9 Cf. Montaigne, pps. 261-265. 
sua precariedade (sua necessidade de segurança e, portanto, de uma vida em comunidade) e, ao mesmo tempo, às pulsões que lhe comandam o espírito, ansioso por liberdade.

Ocorre que esta concessão mínima à cidade, esta quase inação, este deixar correr passivo em que o indivíduo atende sobretudo às suas próprias exigências e, por aí mesmo, ajusta sua conduta ao andamento do cosmos, vão na direção contrária do que Montaigne sustenta no "De poupar a própria vontade". Em primeiro lugar, porque a dosagem de sua aplicação aos cargos políticos não se funda numa necessidade (aliás, típica do individualismo moderno, que Montaigne, para Friedrich, inaugura) de dar livre curso às próprias pulsões, mas numa exigência ética herdada da tradição helenística - a tranquillitas. De tal modo que é uma outra ação, um outro trabalho - ação ou trabalho sobre si - que vêm regular a ação política. Em segundo lugar, porque mesmo a exigência ética não vem restringir o espaço da atuação política, mas, ao contrário, ampliá-lo, vindo fortalecer a ação com vistas à coletividade, tornála mais justa e eficaz. Isto porque se trata de afastar a paixão do domínio da ação. De tal forma que, tanto do lado da ética quanto da política, o ensaísta age - ainda que sobre uma matéria que pede cautela, observação, atenção aos seus próprios movimentos e exigências. É justamente por isso que Montaigne parece passivo: porque respeita rigorosamente a dinâmica de suas próprias pulsões bem como a das pulsões dos homens na história. Mas, o faz somente para adaptar a terapia à matéria, a ação ao objeto; pois, ele não deixa os eventos correrem - apenas observa-os, buscando aprender a maneira correta de agir e esperando o momento propício para intervir, calma e discretamente.

\section{Referencias bibliográficas}

BRAHAMI, Frédéric. Le Scepticisme de Montaigne. Paris: PUF, 1997. FRIEDRICH, Hugo. Montaigne (tradução de Robert Rovini). Paris: Gallimard, 2002. MONTAIGNE, Michel de. Les Essais (édition de Pierre Villey, reéditée par V. L. Saulnier; Col. Quadrige). Paris: PUF, 1999.

Paulo: Martins Fontes, 2001.

Os Ensaios (tradução de Rosemary Costek Abílio). São

SENECA, Lucius Annaeus. De Tranquillitate Animi, in Les Stoïciens (textes traduits par Émile Bréhier et édités par Pierre-Maxime Schuhl). Paris: Gallimard, 1962.

STAROBINSKI, Jean. Montaigne en Mouvement. Paris: Gallimard, 1982. 